\title{
Technological Features of Well Equipment Work Under Production of Oils With Increased and High Viscosity
}

\author{
Tanyana IVANOVA ${ }^{1 *}$, Aleksandr KORSHUNOV ${ }^{2}$ and Nikola ABO ISSA ${ }^{3}$
}

Authors' affiliations and addresses:

${ }^{1}$ Federal State Budgetary Institution of Science

"Udmurt Federal Research Center of the Ural

Branch of the Russian Academy of Sciences", Institute of Mechanics, 426000, T. Baramzinoy str., 34, Izhevsk, Russia

Tchaikovsky Branch "Perm National Research Polytechnic Institute", 617764, Lenin st., 73, Tchaikovsky, Russia

e-mail: tatnic2013@yandex.ru

${ }^{2}$ Federal State Budgetary Institution of Science "Udmurt Federal Research Center of the Ural Branch of the Russian Academy of Sciences", Institute of Mechanics, 426000, T. Baramzinoy str., 34, Izhevsk, Russia

e-mail: maguser_kai@mail.ru

${ }^{3}$ Damascus University, Faculty of Mechanical and Electrical Engineering, P.O.Box 86

Damascus, Syria

e-mail: nicolanu@scsnet.org

\section{*Correspondence:}

Tanyana Ivanova, Federal State Budgetary Institution of Science "Udmurt Federal Research Center of the Ural Branch of the Russian Academy of Sciences“, Institute of Mechanics, 426000, T. Baramzinoy str., 34, Izhevsk, Russia e-mail: tatnic2013@yandex.ru

How to cite this article:

Ivanova, T., Korshunov, A. and Abo Issa, N. (2020). Technological Features of Well Equipment Work Under Production of Oils With Increased and High Viscosity. Acta Montanistica Slovaca, Volume 25 (3), 406-416

DOI:

https://doi.org/10.46544/AMS.v25i3.12

\begin{abstract}
Fields with hard-to-recover reserves include formations with small oil-saturated thickness, low-permeable reservoirs and formations with great depth of occurrence. Premature failures of the well equipment entail oil recovery from these fields. To increase technological efficiency of production of high-viscous oils of the well stock equipped with a walking beam pumping unit (WBPU) it is proposed to use a sucker-rod pump with an external weighting agent. Introduction of this type of pumps will increase the value of the minimum load on a sucker-rod string during its downward stroke, which will reduce the value of amplitude loads. Additional load, created by external weighting agents, will prevent the rod string from hovering due to high hydrodynamic friction forces caused by the pumped fluid's increased and high viscosity. The technological efficiency of introducing this pump in wells with WBPU is demonstrated. Calculations made allow us to determine the necessary weight of heavy bottom according to the produced fluid's viscosity.
\end{abstract}

\section{Keywords}

sucker-rod pump with an external weighting agent, plunger, minimum loads, high-viscous oil. 


\section{Introduction}

The most widespread recovery method for high-viscous oils (HVO) is oil production by means of walking beam pumping unit (WBPU) with chain, hydraulic and screw drives for pumping jack. The main advantages include the possibility of working with small pump rates (from 1.5 to 2 strokes per minute); increasing stroke length to $6 \mathrm{~m}$; reduced metal intensity.

In case of HVO production by means of WBPU the following measures to adapt existing pump equipment to specific conditions are practically used (Adonin, 2013; Aliev et al., 2013; Galikeev et al., 2015; Ivanova et al., 2018; Ivanova et al., 2018; Nasyrov et al., 2011; Novokshonov et al., 2017; Vakhitov, 2010; Zakharov, 2006; Zakharov, 2010):

1) Increase in pump submergence below dynamic level;

2) Use of valves with increased flow section;

3) Selection of pumps according to their fit class (clearance between plunger and cylinder should not be less than $0.12-0.17 \mathrm{~mm}$ )

4) Preliminary calculation and selection of allowable parameters $(n \cdot S)$ of pump operation to prevent rod hovering (Krenicky, 2011; Turygin et al., 2018)

5) Implementation of tubing string with increased diameter (for example replace of $73 \mathrm{~mm}$ pipe by the one with $89 \mathrm{~mm}$ diameter);

6) Use of differential pumps and sinker rods;

7) Oil production from tubing annulus;

8) Application of downhole electric heaters;

9) Application of heating cables;

10) Use of chain drives.

When it is necessary to increase pumping speed, the next methods are applied: increasing tubing diameter from $73 \mathrm{~mm}$ to $89 \mathrm{~mm}$ diameter; stepped tubing string from $73 \mathrm{~mm}$ to $89 \mathrm{~mm}$; addition of weight to sucker rod string bottom; injection of demulsifier in continuous or periodic mode. The efficiency of WBPU in case of HVO production is $25 \%$ less than in case of recovery of oils with small viscosity (Zakharov, 2006).

\section{Material and Methods}

During the production of HVO by means of WBPU hydrodynamic friction forces (resistance) occur. These forces reduce the weight of the rod string and lead to a delay in the movement of the string to the lower boundary value during the downward stroke. Hydrodynamic friction forces also exert considerable influence during upward stroke of rod string, increasing the maximum load at rod hanger centre (RHC) (Blatnický et al., 2020). Thus, the result of these forces' action is the non-synchronism of the movement of the rod string and the horsehead of walking beam unit (Baranov et al., 2017).

An increase in the maximum load and a decrease in the minimum load on the rod string in case of the well exploitation by means of sucker rod pump units under conditions of increased and high viscosity of oil contributes to an increase in the stress concentration in the pump rods, leading to premature failure of the downhole pump equipment (DPE) (Grudz et al., 2020; Khanzhina et al., 2014; Lipanov et al., 2020; Olkhovskaya, 2011; Vasylyshyn et al., 2020).

It was established (Galikeev et al., 2015; Zakharov, 2010) that the growth of the oil viscosity causes a decrease in the parallelism of the movement of the horsehead and the string of pump rod. Significant alternating loads appear on the rod string. Impact loads reduce the life of the equipment, leading to accidents at the wells and therefore reducing the MTBF and the mean time between overhauls.

To increase the technological efficiency of the production of HVO in the conditions of the Arlanskoye field, it is proposed to use a sucker rod pump with an external weighting agent at the well stock equipped with WBPU. The introduction of this type of pumps will increase the value of the minimum load on the sucker rod string during the downward stroke, thereby reducing the value of the amplitude loads. The additional load created by the external weighting agent will prevent the rod string from hovering due to high hydrodynamic friction forces caused by the increased and high viscosity of the pumped fluid (Kuric et al., 2019; Qazizada et al., 2017; Qazizada et al., 2017; Senkevich et al., 2016).

This type of pump consists of two plungers of small and large diameters (Fig. 1). The plungers are connected to each other and located in the pump cylinder at a distance equal to the plungers' length of stroke. The two-plunger system forms two chambers of small and large sizes. Standing and travelling valves are installed in a large diameter plunger. The cylinder is installed on the tubing by means of a pump sitting nipple. A weighting device in the form of a hollow filter element is located in the lower part of the large plunger and is installed outside the tubing. 
The sucker rod pump with an external weighting agent works the following way. When the plungers move down, excessive pressure is formed in the pump cylinder's cavity, causing standing valve closing. Then the travelling valve opens, and the fluid in the large plunger's cavity flows upward in the direction of movement of the rod string. When the plungers of the pump move upward, the travelling valve closes due to the pressure difference above and below the valve. The standing valve opens and the liquid, passing through the filter openings, gets into the working cavity of the larger diameter plunger. Such a circulation of the liquid cleans the filter, which plays the role of weighting weight. This weighting agent helps overcome the forces of hydrodynamic friction during the movement of the pump's plungers and the string of pump rods down. Reducing the amplitude loads due to increase in minimum load allows an extension of the rod string's life, thereby increasing the mean time between failures of the downhole pumping equipment and the overhaul period of the well (Pchela et al., 2019; Václav et al., 2017).

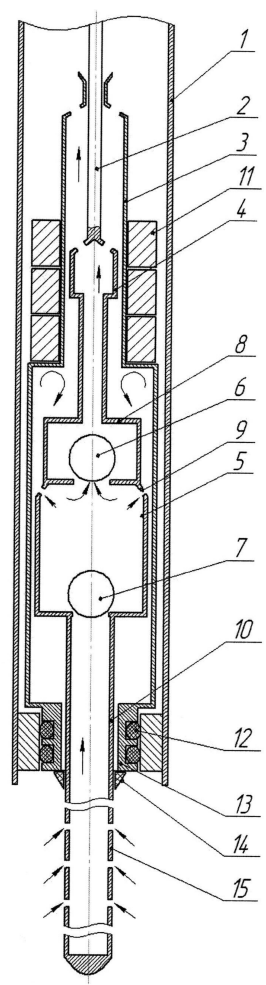

Fig. 1 - Construction of sucker rod pump with external weighting agent: 1 - tubing string; 2 - rod string; 3 - cylinder; 4 -plunger of smaller diameter; 5 - plunger of bigger diameter; 6 - travelling valve; 7 - standing valve; 8 - travelling valve case; 9 - holes; 10 - filter weighting agent; 11 - toroidal weighting agents; 12 - resin rings; 13 - seating place; 14 - bushing-scraper; 15 - filter

In 2017, the main stock of sucker rod pumps of oil-and-gas production department "Arlanneft" was represented by the following types: insert pumps - НВ1Б-29, НВ1Б-32, НВ1Б-44; tubing pumps - НН2Б-44, НH2Б-57.

For wells equipped with WBPU, two versions of design of the sucker rod pump were developed: an assembly with pumps of type НВ1Б-32+ НН2Б-44; an assembly with pumps of type НВ1Б-44+НH2Б-57.

Insert pumps HВ1Б-32, and НВ1Б-44 are the top component of these units, as they have a smaller diameter than the plungers of tube pumps НН2Б-44 and НН2Б-57 located in the lower part. The tubing pump's polished rod is replaced by the one from an insert pump of the same diameter that is unsuitable for further operation. This polished rod is employed in the assembly, giving a possibility to connect both plungers. During attaching this polished rod to the upper plunger, the upper plunger cage from the same pump is used, since it has a thread for connecting to the polished rod. This plunger cage is screwed onto the lower cage of a smaller plunger, polished rod with a larger diameter plunger at the lower end is attached to it. To connect with the rods serving as a weighting agent, the upper cage of the failed pump of the same diameter is also installed in the lower part of the tubing pump's plunger (Bozek, 2013; Kopas et al., 2017).

In the assembly НВ1Б-32 + НН2Б-44, rods with a diameter of $19 \mathrm{~mm}$ and polished rods of $30 \mathrm{~mm}$ are used as the weighting agents. Rods with a diameter of $22 \mathrm{~mm}$ are not used, since the coupling does not pass through the machined conical seat. On a polished rod, it is necessary to replace the existing M30 thread with an M19 thread. It is necessary to do as the free side of the cage installed on the lower end of the larger plunger has an M19 thread. 
To assemble the НВ1Б-44+НН2Б-57 installation kit, it is necessary to prepare the tubing pipe with a length of $5200 \mathrm{~mm}$, inside which the insert pump should be located. This length is specially selected for the size of the insert pump. It is also chosen to ensure the full stroke length and for easy fitting.

The lowering of this assembly inside the well is made the following way. Firstly, a liner made of tubing 2.5" $(73 \mathrm{~mm})$ is lowered. To prevent the weighted bottom assembly from falling, there is a plug at the lower end of the liner. The liner length is determined by the number of rods used for a heavy bottom assembly. Then, using an adapter bushing $2.5 " \mathrm{~m} 2 "$ a filter is screwed, which is also connected to the cylinder of the HН25-57 tubing pump by means of an adapter bushing $2 " \mathrm{n} 2.5$ ".

A tubing fitting pipe with a diameter of $73 \mathrm{~mm}$ and a length of $300 \mathrm{~mm}$ is attached to the pump casing, then an adaptor with a bushing for fastening of a prepared tubing pipe with a length of $5200 \mathrm{~mm}$ is installed. The seating nipple OM-73 $(\mathrm{d}=89 \mathrm{~mm}, \mathrm{~L}=3400 \mathrm{~mm})$ is lowered, after which the tubing string is lowered. Then, the weighted bottom, the plunger of the НН2Б-57 tubing pump, the insert pump НВ1Б-32, and the rod string are connected. For a heavy bottom assembly, rods with a diameter of $22 \mathrm{~mm}$ are used.

\section{Results}

For a sucker rod pump with an external weighting agent, the theoretical feed formula considers the difference in the cross-sectional area of the larger and smaller diameter plungers (Zakharov, 2010)

$$
Q_{T}=1440 \cdot S \cdot\left(F_{b}-F_{m}\right) \cdot n,
$$

where $S$ - length of stroke of polished rod, $\mathrm{m} ; F_{b}$ - plunger cross-sectional area of the pump with the larger diameter, $\mathrm{m}^{2} ; F_{m}$ - plunger cross-sectional area of the pump with the larger diameter, $\mathrm{m}^{2} ; n-$ number of strokes of horsehead, $\min ^{-1}$.

To evaluate the operating efficiency for this type of pumps, theoretical productivity was estimated at minimum, average and maximum work parameters. Thus, for a pump assembly of type НВ1Б-44 + НН2Б-57 (Russia), the theoretical capacity of the pump with a difference in the cross-sectional area of the plungers at $0.0011 \mathrm{~m}^{2}$, with a plunger stroke length of $3 \mathrm{~m}$ and a stroke number of $6 \mathrm{~min}^{-1}$ will be:

$Q_{T}=1440 \cdot 3 \cdot 0.0011 \cdot 6=28.5 \mathrm{~m}^{3} /$ day

The results of the calculations for the rest of the pump assemblies are demonstrated in table 1 .

\begin{tabular}{|c|c|c|c|c|}
\hline \multirow{2}{*}{ № } & \multirow{2}{*}{$\begin{array}{c}\text { Type of pump assembly } \\
\text { Insert pump } \mathrm{x} \text { Tubing } \\
\text { pump }\end{array}$} & \multicolumn{3}{|c|}{ Pump theoretical feed, $m^{3} / d a y$} \\
\hline & & $S \cdot n=3.6$ & $S \cdot n=10.8$ & $S \cdot n=18$ \\
\hline 1 & $27 \times 29$ & 0.5 & 1.4 & 2.3 \\
\hline 2 & $27 \times 32$ & 1.2 & 3.6 & 5.9 \\
\hline 3 & $27 \times 44$ & 4.9 & 14.7 & 24.6 \\
\hline 4 & $27 \times 57$ & 10.3 & 30.8 & 51.3 \\
\hline 5 & $27 \times 68$ & 18.8 & 56.5 & 94.1 \\
\hline 6 & $29 \times 32$ & 0.7 & 2.2 & 3.7 \\
\hline 7 & $29 \times 44$ & 4.3 & 12.9 & 21.6 \\
\hline 8 & $29 \times 57$ & 9.8 & 29.4 & 49.0 \\
\hline 9 & $29 \times 68$ & 15.4 & 46.1 & 76.9 \\
\hline 10 & $32 \times 44$ & 3.6 & 10.7 & 18.6 \\
\hline 11 & $32 \times 57$ & 9.1 & 27.2 & 45.4 \\
\hline 12 & $32 \times 68$ & 14.6 & 43.9 & 73.1 \\
\hline 13 & $44 \times 57$ & 5.2 & 17.1 & 28.5 \\
\hline 14 & $44 \times 68$ & 11.1 & 33.2 & 55.3 \\
\hline 15 & $57 \times 68$ & 5.6 & 16.1 & 26.7 \\
\hline
\end{tabular}

When oil with increased and high viscosity is produced by means of WBPU, the entire unit's operation is complicated by the additional load on the sucker rod string due to the action of hydrodynamic friction. During the downstroke, the rod string is exposed to hydrodynamic resistance, decreasing its weight to zero (Zakharov, 2010). On the contrary, with the rods' reverse stroke (upstroke), forces of hydrodynamic friction cause the load increase. Such an imbalance in the movement of the horsehead of the walking beam and the rod string leads to a deterioration in the whole pumping unit's operation. 
A decrease in the minimum loadand an increase in the maximum load in the sucker rod during the lifting of $\mathrm{HVO}$ result in growing of stress amplitudes in the metal of the rods under an asymmetric loading cycle.

The pumps of a special design with an external weighting agent reduce the hydrodynamic resistance during the movement of the rod string and increase the minimum load. These pumps help reduce the amplitude of the loads and avoid the danger of "hovering" of the rod string during the down stroke (Murcinkova and Krenicky, 2013; Zakharov, 2006).

The calculation of the friction forces (resistance) of sucker-rod downhole pumps with external weighting agent differs from the calculation for WBPU. This is explained by the downward movement of a viscous fluid inside the tubing string during the down stroke of the walking beam's horse head. In WBPU with external weighting agent, this factor is eliminated.

To evaluate the parameters of a sucker rod pump with an external weighting agent, calculations were fulfilled, allowing us to determine the heavy bottom assembly weight depending on the viscosity of the produced fluid.

The equation of the distribution of the fluid flow rate in the tubing:

$$
V=\frac{\partial R}{\partial Z} \cdot \frac{1}{4 \cdot \mu}\left(R_{T}^{2}-r^{2}+\frac{\left(R_{s}^{2}-R_{T}^{2}\right)}{\ln m} \cdot \ln \frac{r}{R_{T}^{2}}\right)+V_{s} \frac{\ln \frac{r}{R_{m}}}{\ln m}
$$

where $m=R s / R_{T}, R s$ - sucker rod radius; $R_{T}$ - tubing internal radius; $V s$ - rod speed at the middle of the stroke, $r$ - current radius of the pipe cross-section, $\mu$ - kinematic viscosity, $\partial R / \partial Z$ - pressure gradient along the pipe axis.

An analysis of equation (2) shows that in case of an increase in sucker rod string overcomes forces of hydrodynamic friction with fluid during the down stroke. Pressure drawdown created in tubing increases fluid pressure since the value of hydrostatic pressure is taken into account.

A smaller value of $m$ helps the string of pump rods to overcome the forces of hydrodynamic friction when the fluid flows down due to gravity. As a result, the force of hydrodynamic pressure changes its sign. An increase in viscosity reduces the hydrostatic pressure almost to zero. This leads to a lack of feed, as a rupture of the flow occurs above the upper plunger of the downhole pump. Therefore, in the case of low viscous fluid flow rates in wells equipped with WBPU with an external weighting agent, the next condition must be met:

$$
\frac{P_{s}+P_{w}}{b}>F_{f}-\pi\left(R_{1}^{2}-R_{s}^{2}\right) \cdot\left(P_{p}+P_{h}-P_{p p}\right)
$$

where $F_{f}$ - the force of hydrodynamic friction of rods; $P_{s}-$ rod weight above the pump; $P_{w}-$ the weigh to the external agent; $b$ - coefficient of rod weight loss in fluid; $P_{h}$ - hydrostatic pressure; $P_{p}$ - hydrodynamic pressure above the upper plunger; $P_{p p}$-pump suction pressure.

In case of higher values of viscous fluid flow rate in the tubing, the following must be ensured:

$$
P_{h}>-P_{p}
$$

The force of hydrodynamic friction of a string of sucker rods against a viscous liquid:

$$
F_{f}=\frac{\pi \cdot P_{p} \cdot R_{T}^{2}}{L}\left(\frac{m^{2}-1}{2 \ln m}+\Delta_{1}^{2}-2 m^{2}\right)-\frac{2 \pi \cdot \mu \cdot L \cdot V}{\ln m}
$$

where $L$ - pump setting depth.

The value of hydrodynamic pressure in the lower part of tubing:

$$
P_{p}=\frac{8 \cdot \mu \cdot L \cdot V p\left(\left(\frac{R_{2}}{R_{T}}\right)^{2}-\frac{m^{2}-1}{2 \ln m}\right)}{R_{T}^{2}\left(1-m^{4}+\frac{\left(m^{2}-1\right)^{2}}{\ln m}\right)}
$$


Taking into account the value of the hydrodynamic pressure, the force of hydrodynamic friction during the downward movement of the rod string will be:

$$
F_{f}=\frac{\mu \cdot L \cdot V}{(1-m)^{2}}\left[\left(\frac{m^{2}-1}{2 \ln m}-m^{2}\right) \cdot\left(\frac{\left(\frac{R_{2}}{R_{T}}\right)^{2}}{1-m^{2}}+\frac{1}{2 \ln m}\right)+\frac{(1-m)^{2}}{6 \ln m}\right]
$$

When the sucker rod string moves upward, the fluid flow rate of the upper plunger of the pump will be added to the flow rate of fluid from the area between the lower plunger and the pump cylinder ("dead" area).

The equation for determining the value of the hydrodynamic friction of a liquid against a string of rods during an upward stroke:

$$
F_{f b}=\frac{68 \cdot \mu \cdot L \cdot V}{(1-m)^{2}}\left[\left(\frac{m^{2}-1}{2 \ln m}-m^{2}\right) \cdot\left(\frac{\left(\frac{R_{2}}{R_{T}}\right)^{2}}{1-m^{2}}+\frac{0,5}{\ln m}\right)+\frac{(1-m)^{2}}{6 \ln m}\right]
$$

The growth of hydrodynamic friction during the downstroke of the string of sucker rods is equal to the force of hydrodynamic friction during the downward movement. This occurs if we take into account the flow rate from the "dead" area of the pump. Then, on the base of diameters of the sucker rods and tubing, the speed of the rod string the value of the weight of the external weighting agent of the sucker rod pump will be determined as:$$
P_{w}>\frac{F_{f}-\pi \cdot\left(R_{1}^{2}-R_{s}^{2}\right) \cdot\left(P_{p}+P_{h}-P_{p p}\right)-P_{s} \cdot b}{b}
$$

We fulfilled the calculation of the hydrodynamic friction force, according to dependences $(1-8)$. To carry out the calculation depending on the radius of the upper plunger of a sucker rod pump with a remote weighting agent we set the following parameters: a single-stage rod string $d_{s}=19 \mathrm{~mm}$, tubing diameter $R_{T}=0.031 \mathrm{~m}$, rod string speed in the middle of the stroke $V=1 \mathrm{~m} / \mathrm{s}$, oil viscosity $\mu=60 \mathrm{mPa} \cdot \mathrm{s}$, and pump setting depth $L=1100$ $\mathrm{m}$. The results of the calculation are demonstrated as graphical dependences on Fig. 1- 3 .

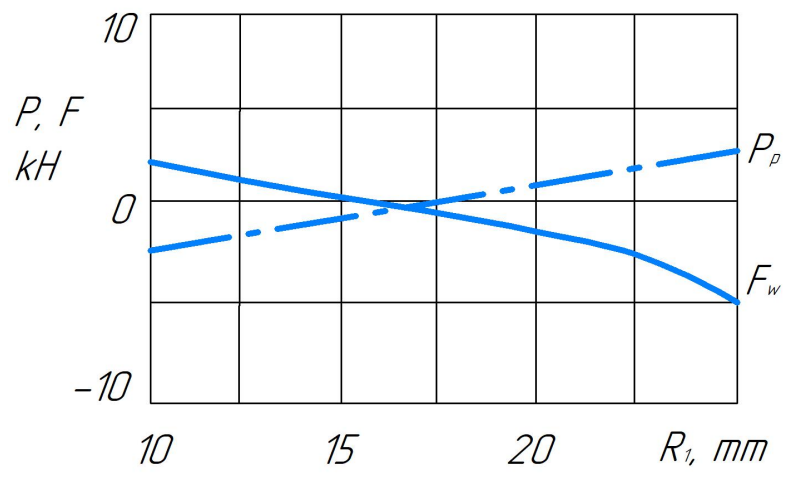

Fig. 1 - Dependence of hydrodynamic friction forces $\left(F_{f}\right)$ during down stroke and hydrodynamic pressure $\left(P_{p}\right)$ on the radius of the upper plunger $R_{l}$

The dependence of the rod string's hydrodynamic friction force during the downward stroke according to the radius of the upper plunger is shown on the graph. The dependence has a curvilinear character and crosses the line of zero value at $R_{I} \approx 21.5 \mathrm{~mm}$. The force's negative values on the left side of the graph indicate that the rod string has to overcome friction forces during the downward movement.

For the hydrodynamic pressure force, the picture is a little different: the dependence crosses the zero value axis under a significantly smaller radius of the upper plunger of the pump. The negative value of the pressure difference completely compensates for the hydrostatic pressure. This will lead to zero pressure above the pump, making the pumping of highly viscous liquid impossible. 


\section{Discussion}

The results of calculating of the minimum load Pmin at rod string depending on the radius of the upper plunger $R_{l}$ in the studied pump type (Fig. 2) show that if the pressure at the pump intake is not taken into account, the minimum load exceeds the weight of the rod string $\left(P_{s}\right)$. This shows that there is no need to install a weighting agent for rod string, as it overcomes the frictional forces. However, taking into account the force of hydrodynamic pressure reduces the value of $P_{\min }$.

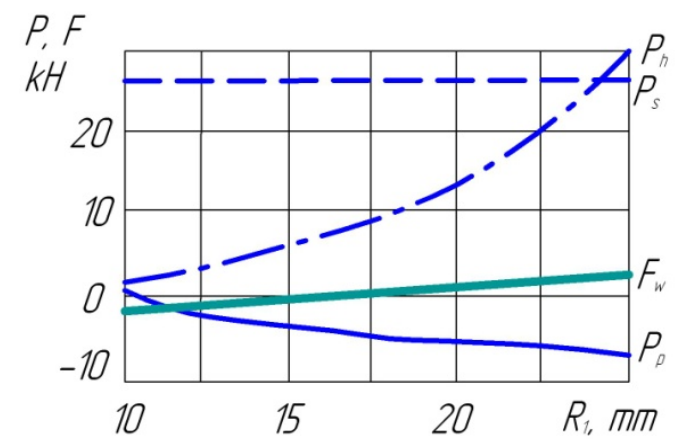

Fig. 2 - Dependence of weight of heavy bottom assembly on oil viscosity

The ratio of the diameters of the tubing and plungers will also affect the value of the minimum load on the rod. The graph shows that the value of $P_{\min }$ is located below the weight of the rod string, which confirms the need to install a heavier bottom assembly.

The dependences of the rod string bottom's weight on the viscosity of the oil for the plunger radii of 10 and $30 \mathrm{~mm}$ are shown in Figure 3.

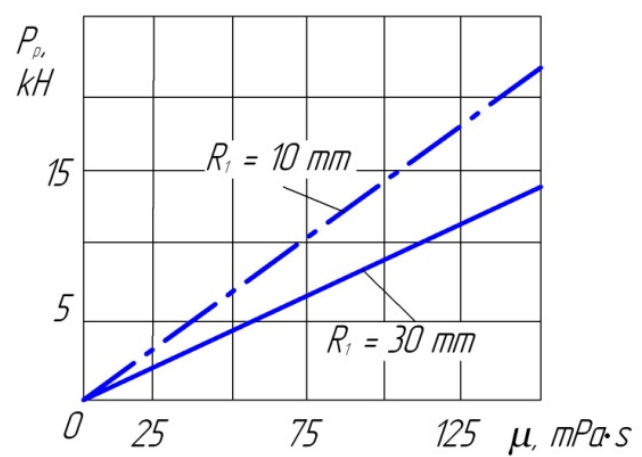

Fig. 3 - The dependence of the weight of the rod string bottom on the viscosity of the oil

This graphical dependence shows that in the interval with increasing radius $R_{1}$, the weight of the rod weighting agent decreases.

To determine the technological efficiency of the introduction of these pumps, 6 wells of the Vyatka area of the Arlanskoye field were equipped with new assembly (Tables 2, 3). Figures 4 and 5 demonstrate dynamograms of the wells with WBPU before and after the introduction of external weighting agent.

Table 2 - Technological efficiency

\begin{tabular}{|c|c|c|c|c|c|c|}
\hline \multirow{2}{*}{ WELL NUMBER } & \multirow{2}{*}{$\begin{array}{l}\text { NUMBER OF } \\
\text { OVERHAULS } \\
\text { BEFORE }\end{array}$} & \multirow{2}{*}{$\begin{array}{l}\text { NUMBER OF } \\
\text { OVERHAULS } \\
\text { AFTER }\end{array}$} & \multicolumn{2}{|c|}{$\begin{array}{l}\text { OVERHAUL } \\
\text { PERIOD }\end{array}$} & \multirow{2}{*}{$\begin{array}{l}\text { AMOUNT OF } \\
\text { ADDITIONALLY } \\
\text { PRODUCED OIL, } \\
\text { THND TON }\end{array}$} & \multirow{2}{*}{$\begin{array}{l}\text { AMOUNT OF } \\
\text { ADDITIONALLY } \\
\text { PRODUCED } \\
\text { FLUID, THND } \\
\text { TON }\end{array}$} \\
\hline & & & before & after & & \\
\hline $2 * * *$ & 3 & 1 & 119 & 362 & 3.70 & 7.15 \\
\hline $4 * * *$ & 6 & 3 & 58 & 119 & 0.55 & 0.87 \\
\hline $6 * * *$ & 4 & 2 & 88 & 180 & 0.76 & 1.44 \\
\hline $8 * * *$ & 4 & 1 & 88 & 362 & 2.29 & 4.34 \\
\hline $6 * * *$ & 3 & 1 & 119 & 362 & 1.40 & 2.31 \\
\hline $5 * * *$ & 3 & 1 & 119 & 362 & 1.99 & 3.60 \\
\hline
\end{tabular}


Table 3 - Characteristics of analyzed wells

\begin{tabular}{|c|c|c|c|c|c|c|c|c|}
\hline $\begin{array}{l}\text { WELL } \\
\text { NUMBER }\end{array}$ & 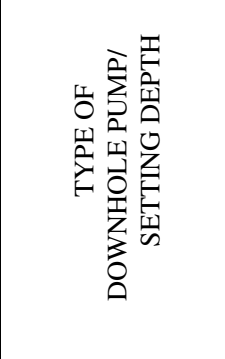 & 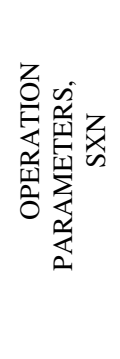 & 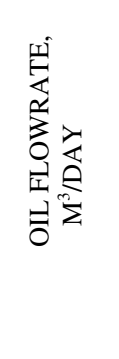 & 立 & 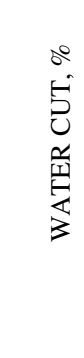 & 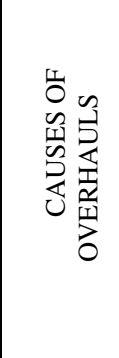 & 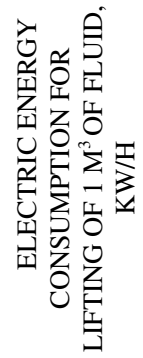 & $\sum_{0}^{\infty}$ \\
\hline \multirow{3}{*}{$2 * * *$} & $\mathrm{H} 44 / 1160 \mathrm{~m}$ & $2.5 \times 4.5$ & 11.5 & 780 & 93 & $\begin{array}{l}\text { Flow } \\
\text { absence }\end{array}$ & & \\
\hline & \multirow{2}{*}{$\begin{array}{c}B 32+H 44 / 1160 \\
m\end{array}$} & $2.5 \times 4.5$ & $9.2-10$ & \multirow[t]{2}{*}{695} & \multirow[t]{2}{*}{93} & \multirow{2}{*}{$\begin{array}{l}\text { Flow } \\
\text { absence }\end{array}$} & & \multirow{2}{*}{$\begin{array}{l}\text { Valve } \\
\text { leakage }\end{array}$} \\
\hline & & $3 \times 4$ & 14.0 & & & & & \\
\hline \multirow{4}{*}{$4 * * *$} & $B 32 / 1300 \mathrm{~m}$ & $2 \times 6$ & 4.5 & 550 & 60 & $\begin{array}{l}\text { Flow } \\
\text { absence }\end{array}$ & 3.2 & \\
\hline & $\begin{array}{c}B 32+H 44 / 1300 \\
m\end{array}$ & $2 \times 6$ & 5.2 & 562 & 60 & $\begin{array}{l}\text { Flow } \\
\text { absence }\end{array}$ & 2.3 & $\begin{array}{lr}\text { Tear } & \text { and } \\
\text { wear } & \text { of } \\
\text { suction } & \text { valve } \\
\text { seat } & \end{array}$ \\
\hline & $\begin{array}{c}B 32+H 44 / \\
1300 m\end{array}$ & $2 \times 6$ & 5.2 & \multirow{2}{*}{640} & \multirow{2}{*}{60} & $\begin{array}{l}\text { Flow } \\
\text { absence }\end{array}$ & 2.3 & $\begin{array}{l}\text { Valve } \\
\text { leakage }\end{array}$ \\
\hline & $\begin{array}{c}B 32+H 44 / 1300 \\
m\end{array}$ & $2 \times 6$ & 6,8 & & & Works & & \\
\hline \multirow[b]{2}{*}{$6^{* * *}$} & $\begin{array}{l}B 32+H 44 / 1160 \\
m\end{array}$ & $1.67 \times 6$ & 6.5 & 747 & 89 & $\begin{array}{l}\text { Flow } \\
\text { absence }\end{array}$ & 1.8 & $\begin{array}{l}\text { Valves plugging } \\
\text { with APRD. I } \\
\text { was noted that } \\
\text { viscous } \\
\text { emulsion } \\
\text { releases during } \\
\text { lifting of sucken } \\
\text { rods and pipes }\end{array}$ \\
\hline & $\begin{array}{l}B 44+H 57 \\
/ 1160 \mathrm{~m}\end{array}$ & $1.67 \times 6$ & 7.2 & 885 & 89 & $\begin{array}{l}\text { Flow } \\
\text { absence }\end{array}$ & 1.05 & $\begin{array}{l}\text { The well was } \\
\text { launched with a } \\
\text { violation of the } \\
\text { technological } \\
\text { mode: during } \\
\text { pressure testing } \\
\text { after well } \\
\text { servicing the } \\
\text { pressure } \\
\text { increased to } 25 \\
\text { atm. In } 4 \\
\text { minutes the } \\
\text { pressure } \\
\text { dropped to } 3 \\
\text { atm. } \\
\end{array}$ \\
\hline \multirow{2}{*}{$8 * * *$} & $B-32 / 1250 m$ & $2.1 \times 4.5$ & 6 & 584 & 89 & $\begin{array}{l}\text { Flow } \\
\text { absence }\end{array}$ & 2.2 & \\
\hline & $\begin{array}{l}B 32+H 44 / \\
1250 \mathrm{~m}\end{array}$ & $2.1 \times 4.5$ & 7.8 & 525 & 89 & Works & 1.4 & \\
\hline \multirow{2}{*}{$5 * * *$} & $H-44 / 1260 \mathrm{~m}$ & $1.6 \times 6$ & 4.7 & 565 & 81 & $\begin{array}{l}\text { Flow } \\
\text { absence }\end{array}$ & & \\
\hline & $\begin{array}{l}B 32+H 44 / \\
1260 \mathrm{~m}\end{array}$ & $1.6 \times 6$ & 6.8 & & 81 & Works & & \\
\hline
\end{tabular}




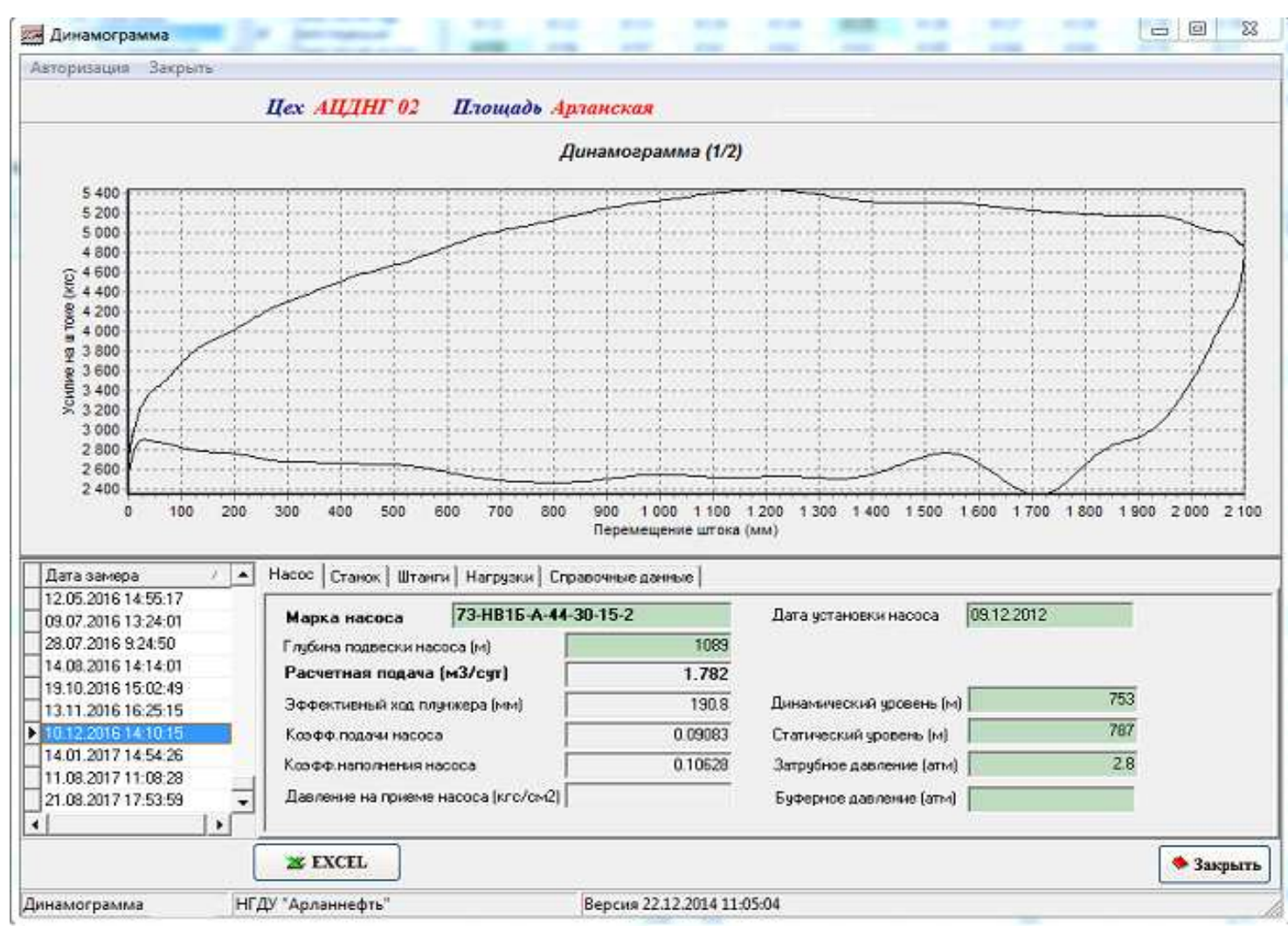

Fig. 4 - Dynamogram of a well equipped with WBPU before the introduction of a pump with an external weighting agent

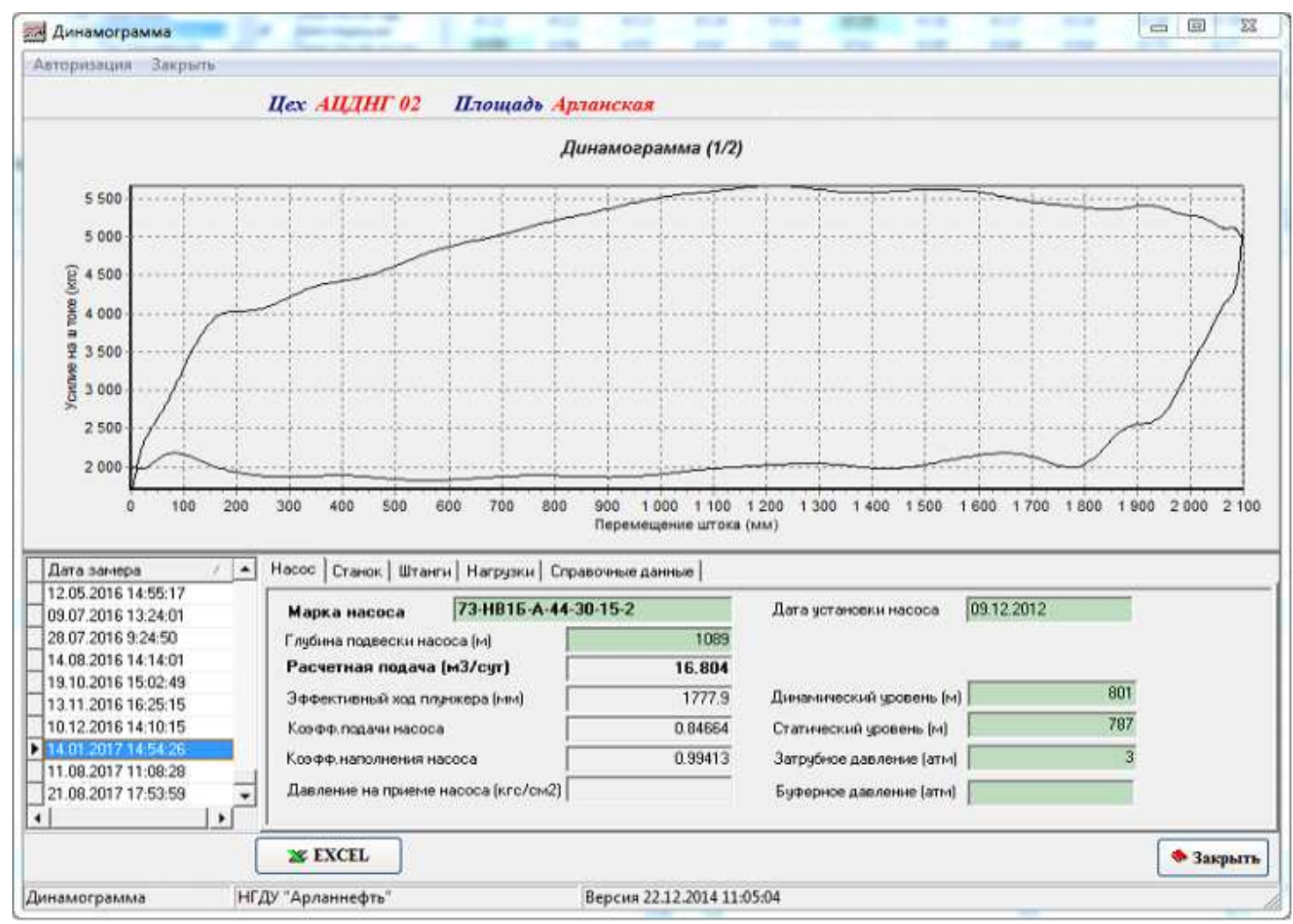

Fig. 5 - Dynamogram of a well equipped with WBPU after the introduction of a pump with an external weighting agent 


\section{Conclusions}

A decrease in the minimum load and an increase in the maximum load in the sucker rod during the lifting of high-viscous oils HVO result in growing of stress amplitudes in the metal of the rods under an asymmetric loading cycle.

The pumps of a special design with an external weighting agent reduce the hydrodynamic resistance during the movement of the rod string and increase the minimum load. These pumps help reduce the amplitude of the loads and avoid the danger of "hovering" of the rod string during the down stroke. When the sucker rod string moves upward, the fluid flow rate of the upper plunger of the pump will be added to the flow rate of fluid from the area between the lower plunger and the pump cylinder ("dead" area). For the hydrodynamic pressure force, the picture is a little different: the dependence crosses the axis of the zero value under a significantly smaller radius of the upper plunger of the pump. The negative value of the pressure difference completely compensates for the hydrostatic pressure. This will lead to zero pressure above the pump, making the pumping of highly viscous liquid impossible. The ratio of the diameters of the tubing and plungers will also affect the value of the minimum load on the rod. The graph shows that the value of $P_{\min }$ is located below the weight of the rod string, which confirms the need to install a heavier bottom assembly. On the base of diameters of the sucker rods and tubing, the rod string's speed the value of the weight of the external weighting agent of the sucker rod pump will be determined.

Calculations made allow us to determine the necessary weight of heavy bottom according to the produced fluid's viscosity.

According to the analyzed well stock, from 04/01/2014 to 05/01/2017 overhaul period MTBO increased by $34 \%$, well productivity increased by $7 \%$ due to a growth of the coefficient of asymmetry of rod loading cycle. Minimum loads for the cycle of oil pumping have grown for al wells, equipped with WBPU with external weighting agent. At the same time, maximum loads increased by the additional weight of the bottom assembly. Such a change in loads favourably affects the well's overhaul.

\section{References}

Adonin, A.N. (2013). Optimum feed rate coefficient of downhole pumps / Oil industry. №5. P.30-33.

Aliev, Sh.N., Huseynov, O.Kh., and Rustamov, E.M. (2013). Sucker rod pumps with double-action / Oil industry. №11. P.30-32.

Baranov, M.N., Bozek, P., Prajova, V., Ivanova, T.N., Novokshonov, D.N. and Korshunov, A.I. (2017). Constructing and calculating of multistage sucker rod string according to reduced stress. In Acta Montanistica Slovaca. Vol. 22, no. 2, 107-115.

Blatnicky, M., Saga, M., Dizo J. and Bruna M. (2020). Application of Light Metal Alloy EN AW 6063 to Vehicle Frame Construction with an Innovated Steering Mechanism, Materials, Vol.13, Issue 4, Article No: 817 , DOI: $10.3390 / \mathrm{ma} 13040817$.

Bozek, P. (2013). Robot path optimization for spot welding applications in automotive industry. In Tehnicki Vjesnik - Technical Gazette. Vol. 20, No. 5, 913-917.

Galikeev, I.A., Nasyrov, V.A. and Nasyrov, A.M. (2015). Operation of oil fields in the complicated conditions. Izhevsk : Paracelsus Print. 353.

Grudz, V., Grudz, Y., Zapukhliak, V., Chudyk, I., Oberezhny, L., Slobodyan, N. and Bodnar, V. (2020). Optimal gas transport management taking Into account reliability factor. Management Systems in Production Engineering. Vol. 28, issue 3. 202-208.

Ivanova, T.N., Baranov, M.N., Bozek, P. and Korshunov, A.I. (2018). Design, technical and technological solutions increasing the productivity of downhole pumping equipment. Jaroměr, Czech Republic: Ing. Jan Kudláček.

Ivanova, T.N., Korshunov, A.I. and Koretckiy, V.P. (2018). Dual Completion Petroleum Production Engineering for Several Oil Formations Management Systems in Production Engineering. Volume/Issue: Volume 26: Issue 4. 217-221.

Qazizada, M. E., Pivarciova, E. and Bialy, W. (2017). Centrifugal pump characteristics computation and reliability evaluation at variable speed driven. ICCT: $5^{\text {th }}$ International Conference on Chemical Technology, Mikulov. 
Qazizada, M. E., Pivarciova, E. and Bialy, W. (2017). Comparison of Gear and Peripheral pumps performance, evaluation of their reliability at operation region International Journal of Safety Science Vol. 01, No. 02, pp. 29-39.

Khanzhina, V., Kovalev, A. and Zinoviev A. (2014). Justification of Well Type and Design Depending on Depletion Mechanism of High-Viscosity Oil Production. Applied Mechanics and Materials, vol. 698, Trans Tech Publications, Ltd., Dec. pp. 674-678., doi:10.4028/www.scientific.net/amm.698. 674.

Kopas, P., Saga, M., Baniari, V., Vasko, M. and Handrik, M. (2017). A plastic strain and stress analysis of bending and torsion fatigue specimens in the low-cycle fatigue region using the finite element methods. XXI Polish-Slovak Scientific Conference Machine Modeling And Simulations MMS 2016, Procedia Engineering, Volume: 177, 526-531.

Krenicky, T. (2011). Implementation of Virtual Instrumentation for Machinery Monitoring. In: Scientific Papers: Operation and Diagnostics of Machines and Production Systems Operational States: Vol. 4, RAM-Verlag, Lüdenscheid, 5-8.

Kuric, I., Cisar, M., Tlach, V., Zajacko, I., Gal, T. and Wiecek, D. (2019). Technical Diagnostics at the Department of Automation and Production Systems. In Intelligent Systems in Production Engineering and Maintenance, Advances in Intelligent Systems and Computing, Volume: 835, 474-484.

Lipanov, A., Lechev, A., Ovcharenko, P., Delgado Sobrino, D., Kolesnikova, L. and Stherkov, K. (2020). Selection of optimal modes of obtaining broad fractions of light hydrocarbons from oil-associated gas at oil production sites. Acta Montanistica Slovaca, Volume 25, Number 1, 1-13.

Murcinkova, Z. and Krenicky, T. (2013). Applications utilizing the damping of composite microstructures for mechanisms of production machines and manipulator devices. In: SGEM 2013: 13th Int. Multidisciplinary Sci. Geoconf. Vol. 1: 16-22 June, Albena, Bulgaria. Sofia: STEF92 Technology, 23-30.

Nasyrov, V.A., Shliapnikov, Iu.V. and Nasyrov A.M. (2011). Water production of wells and its influence on complicating factors in oil production. EkspozitsiiaNeftGaz. // Exposition Oil and Gas. -2011. №2, special issue, April. 14-17.

Novokshonov, D.N., Baranov M.N. and Ivanova, T.N. (2017). Reliability Improvement of Sucker-Rod String at Directional and Horizontal Wells // «Intelligent Systems in Manufacturing ». - Izhevsk: Publishers house: Kalashnikov Izhevsk State Technical University. Vol 15, № 1.110 - 113.

Olkhovskaya, V.A. (2011). Underground hydromechanics. Non-Newtonian oil filtration. - M.: JSC VNIIOENG. 221.

Pchela, K.V., Gornov, D.A., Kireev, I.I., Bagryantsev, M.S., Manasyan, A.E., Amirov, A.A., Kashaev, D.V. and Sereda, I.A. (2019). Optimization of technological solutions in the development of deposits of superviscosity oil based on data from core studies and oil properties. Oil. Gas. Novatsii. No.7, pp. 79-85.

Senkevich, I., Grigorov, B.A. and Mardupenko, A.A. (2016) Technological Processing of Oil Waste. Oil Gas Res, 2:115.

Turygin, Y., Bozek, P., Abramov, I. and Nikitin Y. (2018). Reliability determination and diagnostics of a mechatronic system. Advances in Science and Technology Research Journal. Vol. 12, iss. 2, 274-290.

Václav, Š., Jurko, J. and Lecký, Š. (2017). Allowance treatment static designed couple and repeatable precision in assembly. In MATEC Web of Conferences [elektronický zdroj], Vol. 137, Modern Technologies in Manufacturing (MTeM 2017 - AMaTUC), Cluj-Napoca, Romania, October 12-13, 2017 (2017), online, [6] pp. DOI: $10.1051 /$ matecconf/201713704007.

Vakhitov, T.M. (2010). Integrated solutions to improve the reliability of downhole equipment operation in difficult conditions at the fields of JSOC Bashneft. Magazine "Engineering Practice".№ 6.

Vasylyshyn V., Taras, I., Bekish, I., Kornuta, O. and Kornuta, V. (2020). Partial cases of stressed-deformed condition of casing and pump compressor pipes. Management Systems in Production Engineering. Vol. 28, issue 2. 97-103.

Zakharov, B.S. (2006). Piston and Plunger Pumps for Oil: (Collection of Articles and Patents. Moscow, JSC "VNIIOENG".

Zakharov, B.S. (2010). Special types of sucker-rod pumps.Moscow, JSC "VNIIOENG". 